\title{
AC-DC PFC Converter Using Combination of Flyback Converter and Full-bridge DC-DC Converter
}

\author{
Moh. Zaenal Efendi, Abdul Rizal, Aldi Erzanuari, Suryono, Novie Ayub \\ Windarko
}

\author{
Electro-industrial Engineering Study Program, \\ Department of Electrical Engineering, Politeknik Elektronika Negeri Surabaya \\ Kampus PENS, Keputih Sukolilo, Surabaya \\ E-mail: zenefendi@gmail.com
}

\begin{abstract}
This paper presents a combination of power factor correction converter using Flyback converter and Full-bridge dc-dc converter in series connection. Flyback converter is operated in discontinuous conduction mode so that it can serve as a power factor correction converter and meanwhile Full-bridge dc-dc converter is used for dc regulator. This converter system is designed to produce a 86 Volt of output voltage and 2 A of output current. Both simulation and experiment results show that the power factor of this converter achieves up to 0.99 and meets harmonic standard of IEC61000-3-2.

Keywords: Flyback Converter, Full-bridge DC-DC Converter, Power Factor Correction.
\end{abstract}

\section{INTRODUCTION}

Generally, electronic equipments need a dc power source. However, the power source provided by electric grid is an ac power source. Therefore, its needs a rectifier circuit which is used to transform the AC power source to the DC power source. The rectifier circuit requires a capacitor as filter to reduce the output voltage ripple. But, the usage of capacitor causes the current harmonics and the current distortion, so that the rectifier circuit has a low power factor.

To reduce the harmonics and to improve the power factor can be done by several methods. The first method is adding a large inductor filter [1]. But, this method is not commonly used because the rectifier circuit is heavier, because it works at low frequency of $50-60 \mathrm{~Hz}$. A good method is adding preregulator of power factor correction converter known as two stages power factor correction converter. The most common two stages power factor correction converter used are boost converter [2], [3], buck converter [4], [5], buck-boost converter [6], [7] and other types of dc-dc converter [8], [9]. Two stages power factor correction converter can produce sine input current, low harmonics and high power factor. 
This paper presents and develops a new configuration of two stages power factor correction converter combining Flyback Converter and Fullbridge dc-dc converter in series connection. This configuration is designed to produce high power factor and low input current harmonics that meets the international harmonic standard of IEC6100-3-2 [10].

The block diagram of the two stages power factor correction converter proposed is shown in Figure 1.

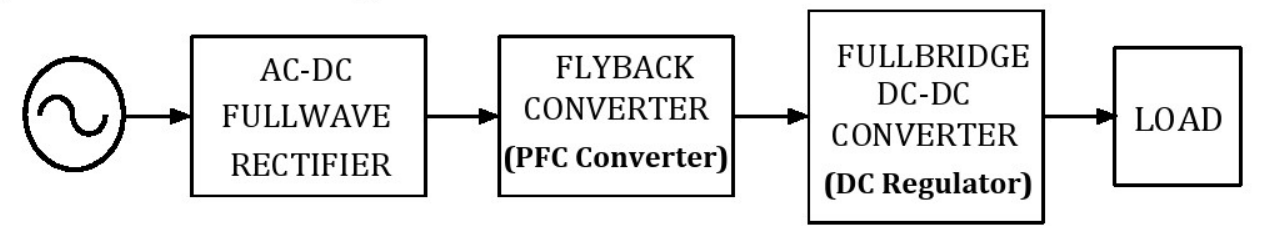

Figure 1.Block diagram of the proposed of two stages power factor correction converter

\section{CONVERTER CONFIGURATION}

Circuit configuration of the two stages power factor correction converter proposed in this paper is shown in Figure 2. This configuration uses a Flyback converter as a pre-regulator of power factor corrector. The Flyback converter is series connected to a Full-bridge dc-dc converter in two stages.

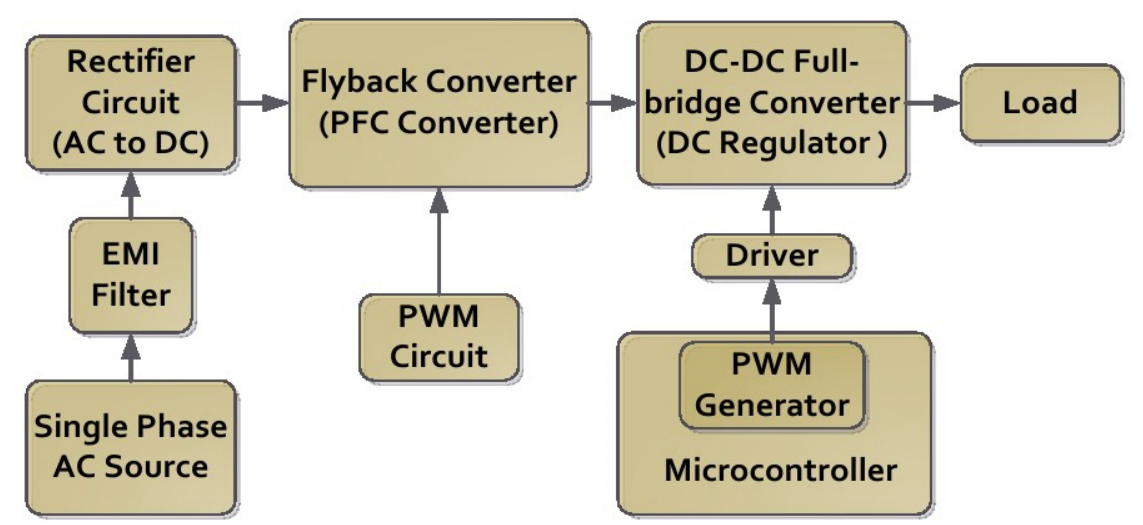

Figure 2. The block diagram of system

Based on the block diagram as seen in Figure 2, the converter system uses two converters. They are Flyback converter and Full-bridge dc-dc converter in series connection. The complete circuit is shown in Figure 3.

The Flyback converter operates in discontinuous conduction mode. Hence, if the converter operates in discontinuous conduction mode, the converter will have a high power factor [11], [12].

Basically, Flyback converter, which is shown in Figure 4(a), is used as power factor corrector and operates in discontinuous conduction mode. It has an magnetizing inductor $\left(L_{m}\right)$ and other components. An input current and a magnetizing current waveforms of Flyback converter is shown in 
Figure 4(b). This converter has an input resistance $\left(R_{i}\right)$ that is calculated from the input voltage $V_{i(t)}$ and the input current $i_{i(t)}$ at one switching period.

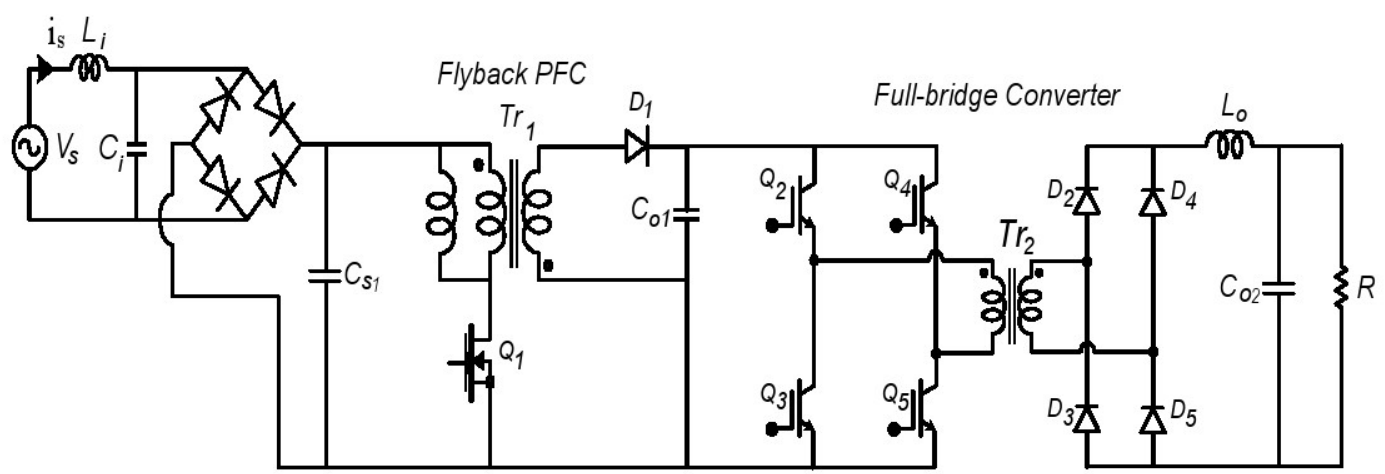

Figure 3. The circuit of AC-DC PFC Converter using combination of Flyback Converter and Full-bridge DC-DC Converter

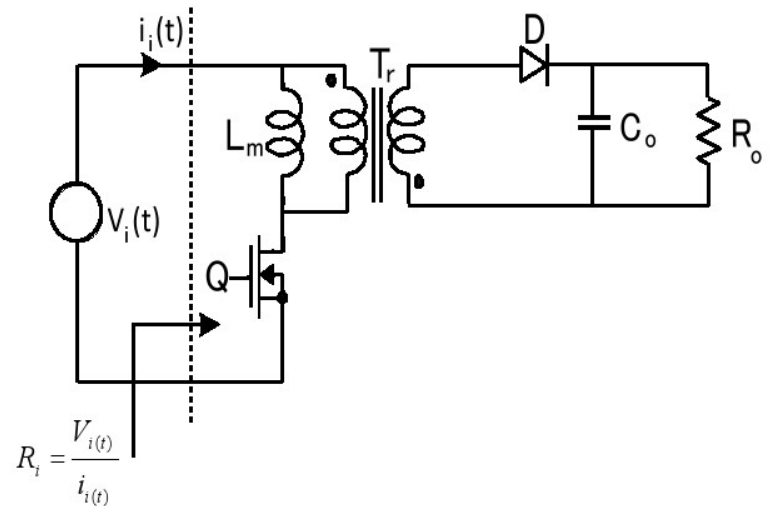

(a)

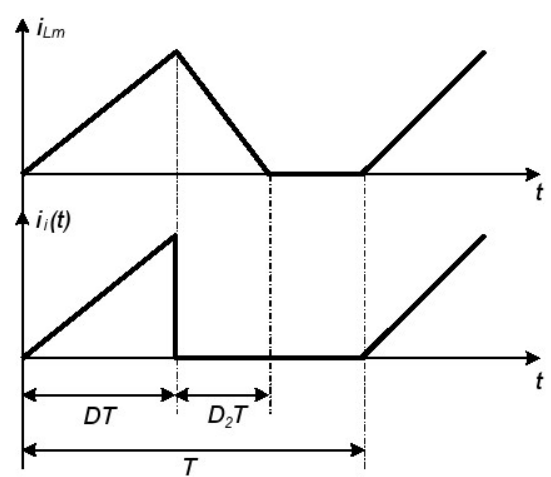

(b)

Figure 4. (a)Flyback converters in discontinuous conduction mode; (b) Waveform of inductor magnetizing and input current

The input resistance of the converter system can be calculated using Equation 1:

$$
R_{i}=\frac{V_{i(t)}}{i_{i(t)}}
$$

According to Figure 4(b), the input current is determined in Equation 2:

$$
i_{i(t)}=\frac{\frac{1}{2} i_{l m} D T}{T}
$$

where $i_{L m}$ is magnetizing inductor current, $D$ is the duty ratio and $T$ is the switching period. The magnetizing inductor current can be calculated by Equation 3: 


$$
i_{l m}=\frac{V_{i(t)}|\sin \omega t| D T}{T}
$$

where $V_{i(t)}|\sin \omega t|$ is the input voltage. If the Equation 3 is substituted into Equation 2, the input current become as Equation 4:

$$
i_{i(t)}=\frac{\frac{V_{i(t)}|\sin \omega t| D T}{2 L_{m}} D T}{T}=\frac{V_{i(t)}|\sin \omega t| D^{2} T}{2 L_{m}}
$$

Finally, Equation 4 is substituted into the Equation 1, thus the input resistance is determined in Equation 5:

$$
R_{i}=\frac{V_{i(t)}}{i_{i(t)}}=\frac{2 L_{m}}{D^{2} T}
$$

The Equation 5 shows the resistance $\left(R_{i}\right)$ depends on the value of magnetizing inductance, switching period, and duty ratio. If the Flyback converter operates in discontinuous conduction mode and in constant duty ratio, the input resistance becomes constant. Therefore, the shape of the input current waveform $i_{i(t)}$ follows the shape of the input voltage waveform $V_{i(t)}$ and the Flyback converter becomes as power factor corrector.

After processing Flyback converter as PFC converter, to obtained output voltage regulation, the Full-bridge dc-dc converter is connected on the converter system. The circuit of the Full-bridge dc-dc converter is shown in Figure 5 and it is designed in continuos mode operation. The Full-bridge dcdc converter is designed using Equation 6 to Equation 8.

Assume that $\mathrm{d}$ is duty cycle, then:

$$
d=\frac{N_{1} \times V_{o}}{2 \times N_{2} \times V_{\text {in }}}
$$

The filter inductor can be obtained from:

$$
L_{c r i}=\frac{(1-d)}{4} \times R T
$$

And, the filter capacitor is:

$$
C_{o}=(1-d) \times \frac{V_{o}}{32 L_{o} f^{2} \Delta V_{o}}
$$




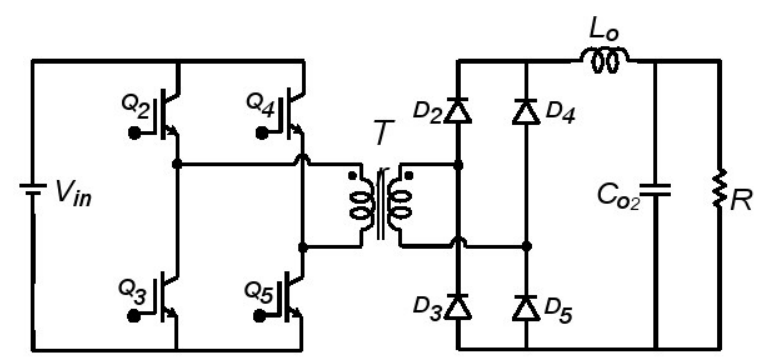

Figure 5. Circuit of Full-bridge dc-dc converter

\section{SIMULATION AND EXPERIMENT}

The prototype of AC-DC PFC Converter Using Combination of Flyback Converter and Full-bridge DC-DC Converter that has been discussed previously is designed with the parameters as seen in Table 1 and Table 2 to meets the requirement of converter operation. Actually, this converter can be implemented for power supply of all of electronics equipment. However, in this paper, converter can be applied as battery charger. The battery used for this experiment has a 72 Volt of voltage that consists of 6 pieces of 12 Volt of battery. So, to comply the requirement of charging voltage, the output voltage of converter system is set at 86 Volt.

To ensure the converter operates in a good performances, it is simulated using SCAT K.460PRI software. The simulation circuit shown in Figure 6 is built based on the circuit on Figure 3 and the parameters that used in this circuit are declared in Table 1 and Table 2. The parameters observed are input voltage, input current, harmonic spectrum, output voltage, and output current.

Table 1. Parameters of Flyback PFC converter

\begin{tabular}{|c|c|}
\hline Parameter & Value \\
\hline AC input voltage $\left(V_{i}\right)$ & 220 Volt \\
\hline Output voltage $\left(V_{o 1}\right)$ & $120 \mathrm{Volt}$ \\
\hline Switching frequency $\left(f_{s}\right)$ & $25 \mathrm{kHz}$ \\
\hline Switch $Q_{1}$ & IGBT $1 \mathrm{MBH} 60-100$ \\
Diode $D_{1}$ & STTH60L06C \\
\hline Transformer $T_{r 1}$ & $\mathrm{~N}_{1}: \mathrm{N}_{2}=6: 4$ \\
\hline Capacitor $C_{o 1}$ & $680 \mu \mathrm{F}, 450$ Volt \\
\hline
\end{tabular}

Table 2. Parameters of Full-bridge dc-dc converter

\begin{tabular}{|c|c|}
\hline Parameter & Value \\
\hline Input voltage $\left(V_{i(f b)}=V_{o 1}\right)$ & 120 Volt \\
\hline Output voltage $\left(V_{o 2}\right)$ & $86 \mathrm{Volt}$ \\
\hline Switching frequency $\left(f_{s}\right)$ & $25 \mathrm{kHz}$ \\
\hline Inductor $L_{o}$ & $866 \mu \mathrm{H}$ \\
\hline Switch $Q_{2-5}$ & IGBT $1 \mathrm{MBH} 60-100$ \\
\hline Diode $D_{2-5}$ & $\mathrm{STTH}_{2} 60 \mathrm{LC} \mathrm{C}$ \\
\hline Transformer $T_{r 2}$ & $\mathrm{~N}_{3}: \mathrm{N}_{4}=16: 14$ \\
\hline Capacitor $C_{o 2}$ & $68 \mu \mathrm{F}, 250 \mathrm{Volt}$ \\
\hline
\end{tabular}




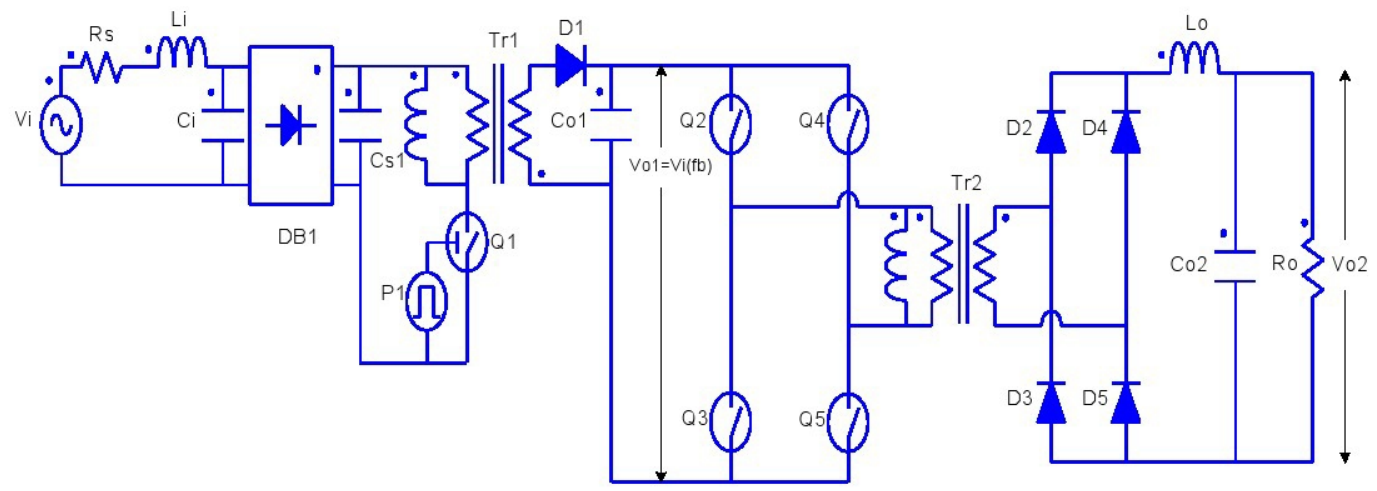

Figure 6. Simulation circuit of converter

The waveforms of the input voltage and the input current are shown in Figure 7. Also, Figure 7 shows that the converter has high power factor of 0.9946, meets Harmonics standard IEC61000-3-2 class.
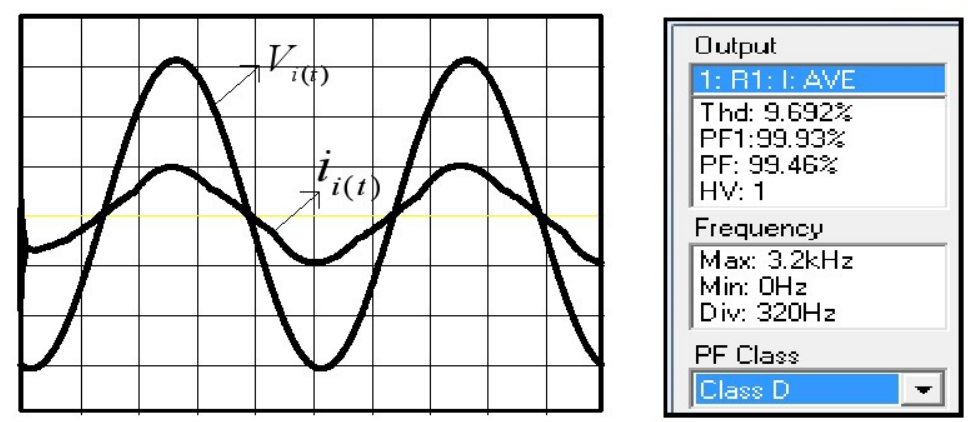

Figure 7. Wavefoms of input voltage and input current and power factor $(\mathrm{pF})$ of converter

Futhermore, the converter is built using above parameters in real circuit. Experiment about the circuit is done using power harmonic analyzer Fluke 41B. The parameters that have been observed are the input current, the input voltage, power factor, and current harmonic spectrum. Figure 8 shows the values of the input parameters which are measured by Fluke 41B and Figure 9 shows the input current waveform, the input voltage waveform and the current harmonic spectrum.

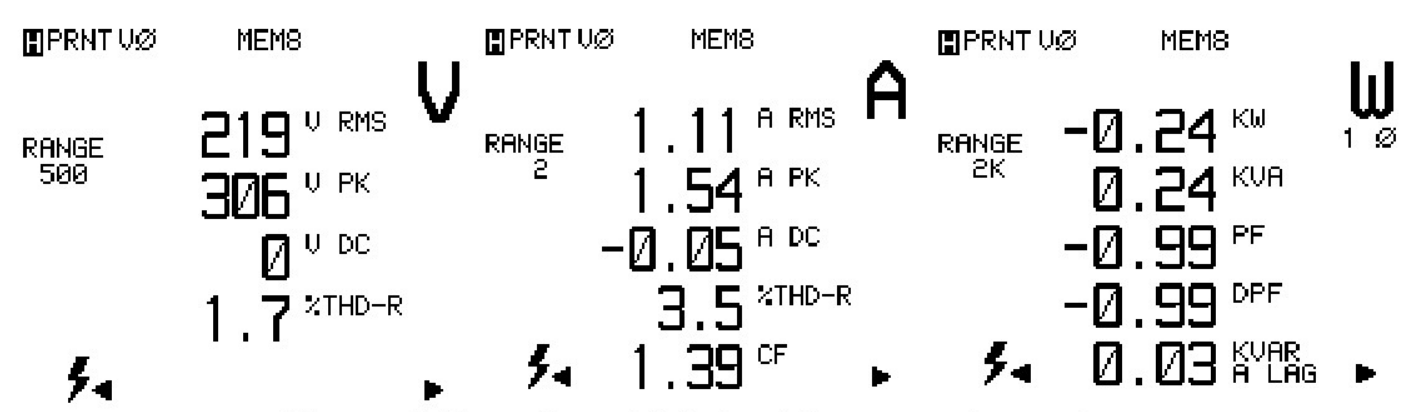

Figure 8. Experimental data of the converter system 


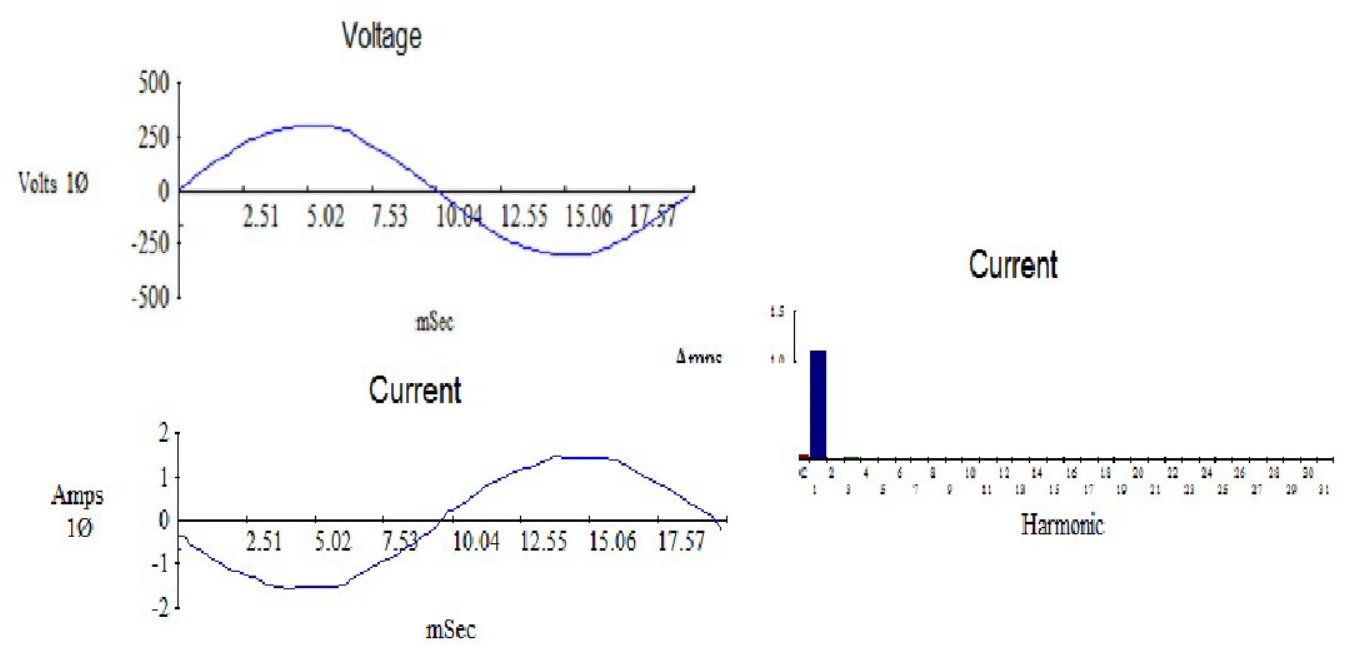

Figure 9. Waveforms of the input voltage and current and the current harmonic spectrum

According to Figure 8, maximum power factor measured by power harmonic analyzer is 0.99 and the Total Harmonics Distotion of the input current $\left(T H D_{i}\right)$ is $3.5 \%$ to $8.2 \%$. The complete results of the experiment are also presented in Table 3. Based on the data in Table 3, on the nominal currect, it can be achived the highest power factor (near unity) and low harmonics.

To know the converter meets harmonics standards, it is made a comparison between the current harmonic spectrum of system testing and harmonic standard of class A and class D. Figure 10(a) and 10(b) are shown this comparation. According to its, the proposed converter system and meets harmonics standards of IEC61000-3-2 class A so that it can be implemented for power supply of audio equipment and dimmer circuit of incandescent lamps. And also it has low harmonics input current meets the standards of IEC61000-3-2 class D so that it can be implemented for power supply of computers and monitors.

Table 3. Experiment result of the converter

\begin{tabular}{|c|c|c|c|c|c|}
\hline $\mathbf{V}_{\mathbf{i}} \mathbf{( V )}$ & $\mathbf{I}_{\mathbf{i}}(\mathbf{A})$ & $\mathbf{V}_{\mathbf{o}} \mathbf{( V )}$ & $\mathbf{I}_{\mathbf{o}}(\mathbf{A})$ & $\mathbf{p F}$ & $\mathbf{T H D i} \mathbf{( \% )}$ \\
\hline 220 & 1.12 & 86 & 2 & 0.99 & 3.5 \\
\hline 220 & 0.9 & 86 & 1.8 & 0.99 & 4.8 \\
\hline 220 & 0.81 & 86 & 1.6 & 0.98 & 5.2 \\
\hline 220 & 0.7 & 86 & 1.3 & 0.97 & 5.2 \\
\hline 220 & 0.57 & 86 & 1 & 0.97 & 5.9 \\
\hline 220 & 0.46 & 86 & 0.8 & 0.95 & 8.2 \\
\hline
\end{tabular}




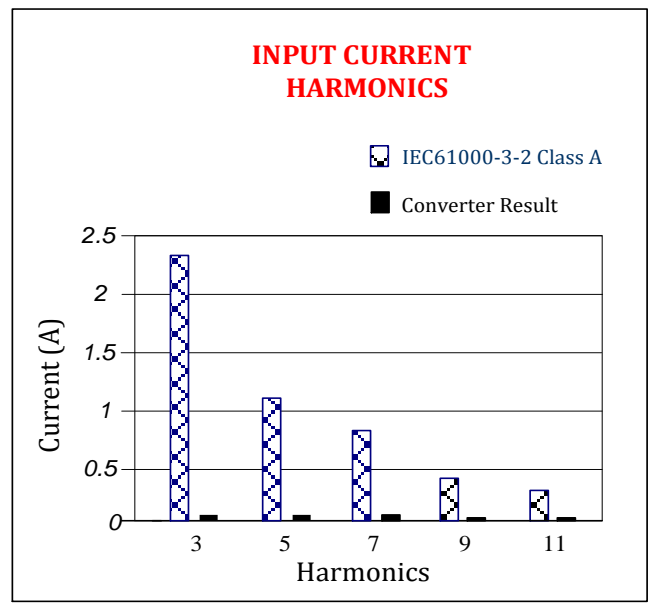

(a)

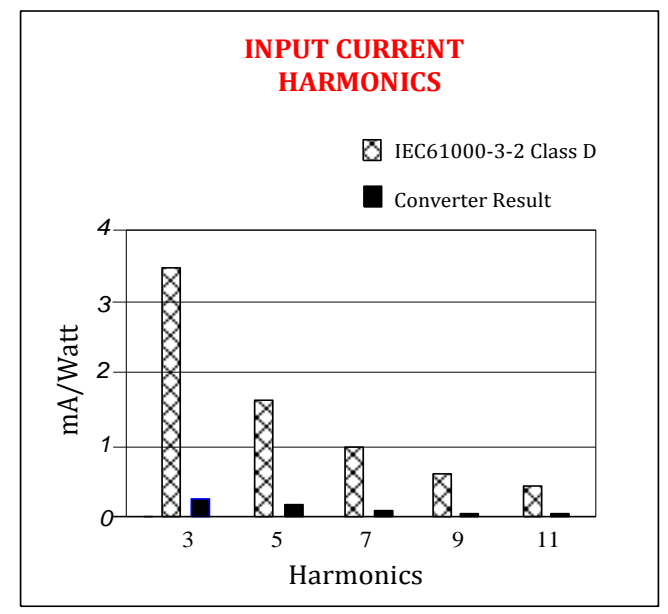

(b)

Figure 10. Comparison of input current harmonics of class A and class D

\section{CONCLUSION}

This paper presented about the combination of AC-DC Flyback converter with full bridge dc-dc converter that has power factor corrector. According to both simulation and experimetal results, this converter system has a high power factor up to 0.99 and low harmonics input current and meetsharmonics standard of IEC61000-3-2 class A and class D.

\section{Acknowledgements}

This paper is published based on the research supported by Research Unit of Politeknik Elektronika Negeri Surabaya (PENS) to Energy and Transportation Research Centre, budgeting year of 2014. We would thank chairman and staff of Research Unit of PENS.

\section{REFERENCES}

[1] Arthur W. Kelly, Rectifier Design for Minimum Line-Current Harmonics and Maximum Power Factor, IEEE Transaction on Power Electronics, Vol. 7, No. 2, April, 1992.

[2] Dragan Maksimovic, Robert W. Erickson, Universal input, High Power Factor Boost Doubler Rectifiers, IEEE Applied Power Electronics Conference, 1995.

[3] Seleme Isaac Jr. Seleme, Lenin Martins Ferreira Morais, Arthur Hermano Rezende Rosa, Leonardo Antônio Borges Torres, Stability in Passivitybased BoostConverterController forPower Factor Correction, European Journal of Control, Volume 19, Issue 1, January 2013.

[4] Hisahito Endo, Takashi Yamashita, Toshiyuki Sugiura, A High Power Factor Buck Converter, IEEE Applied Power Electronics Conference, 1992. 
[5] J.M. Alonso, M.A. Dalla Costa, C. Ordiz, Integrated Buck-flyback Converter as a High-power-factor Off-line Power Supply, Industrial Electronics IEEE Trans, 55 (3), 2008.

[6] M.C. Ghanem, K. Al-Haddad, G. Roy, A New Single Phase Buck-Boost Converter With Unity Power Factor, In Conference Record of The 1993 IEEE Industry Applications Society Annual Meeting, IAS 1993.

[7] Huai Wei, Power Factor Correction Circuits, Power Electronics Handbook (Third Edition), 2011.

[8] Bor-ren Lin, Tsang-sum Huang, Zero Current SwitchingCukConverter forPower Factor Correction, Electric Power Systems Research, Volume 41, Issue 2, May 1997.

[9] Mohd Rodhi Sahid, Abdul Halim Mohd Yatim, Modeling and Simulation of a New Bridgeless SEPIC Power Factor Correction Circuit, Simulation Modelling Practice and Theory, Volume 19, Issue 2, February 2011.

[10]Schaffner EMC,IEC61000-3-2 Harmonics Standard Overview, May 2006.

[11]Robert W Erickson, M. Madigan, S. Singer, Design of a Simple High Power Factor Rectifier Based on Flyback Converter, IEEE Applied Power Electronics Conference, 1990.

[12]Zhang Jun, D.D.-C. Lu, Sun Ting, Flyback-based Single-stage PowerFactor-correction Scheme with Time-multiplexing Control, Industrial Electronics IEEE Trans, 57 (3), 2010. 